\title{
The nature of emotional support and counselling provision for people with sight loss in the United Kingdom
}

Pybis, J., Thurston, M., Dennison, C., Broom, M. \& Miller, A.

This is the accepted manuscript, ( $)$ the authors, of an article published by Sage in the British Journal of Visual Impairment 2016, available from https://dx.doi.org/10.1177/0264619616633884 


\section{Abstract}

People with sight loss in the United Kingdom are known to have lower levels of emotional wellbeing and to be at higher risk of depression. Consequently 'having someone to talk to' is an important priority for people with visual impairment. An online survey of the provision of emotional support and counselling for people affected by sight loss across the UK was undertaken. The survey was distributed widely and received 182 responses. There were more services offering 'emotional support', in the form of listening and information and advice giving, than offered 'counselling'. Services were delivered by providers with differing qualifications in a variety of formats. Waiting times were fairly short and clients presented with a wide range of issues. Funding came from a range of sources, but many felt their funding was vulnerable. Conclusions have been drawn about the need for a national standardised framework for the provision of emotional support and counselling services for blind and partially sighted people in the UK.

\section{Keywords}

Emotional support, counselling, visual impairment, survey, service provision

\section{Introduction}

There are almost two million people in the United Kingdom affected by sight loss. An ageing demographic means this figure is predicted to double by 2050 , as one in five 
people aged 75 and one in two aged 90 and over live with sight loss (Access Economics, 2009). Sight loss is known to increase the risk of depression (Osborn, Fletcher, Smeeth et al.,2003; Gosney, Victor \& Nyman, 2010) and can present a suicide risk amongst elderly people ( Waern, Rubenowitz, Runeson , Skoog, Wilhelmson \& Allebeck, 2002). A secondary analysis of national survey data (McManus and Lord, 2012) found that, after standardising for age and sex, people in the UK with sight loss, compared with those with no impairment, were:

- seven times more likely to have been feeling unhappy or depressed a lot more than usual (14\% vs. $2 \%)$;

- nine times more likely to have been feeling worthless recently a lot more than usual $(9 \%$ vs. $1 \%)$

- three times more likely to not feel optimistic about the future (9\% vs.3\%);

- nine times more likely never to feel useful ( $9 \%$ vs. $1 \%)$;

- five times more likely to never feel close to others ( $5 \%$ vs. $1 \%)$.

In addition, the mean mental wellbeing score was lower among people with sight loss than among people without impairment, and the difference was more pronounced among people of working age than among people post working age (aged 65 and over).

These findings point to a need for people with sight loss to access emotional support and/ or counselling. In the 'Seeing it my way' consultation, 1182 people with sight loss in the UK endorsed ten outcomes that they wanted to be achieved which 
included "that I have someone to talk to" (UK Vision Strategy, 2011). Being offered information, advice and the appropriate support at the point of diagnosis, by a trained professional or information service; being informed about emotional support services and being given dedicated time and ongoing support to help gain confidence and achieve a sense of well-being for as long needed; and, access to facilitated peer support groups were key to this. Cairns et al (2009) identified that social and emotional issues and the need for counselling and emotional support were among the 'top 10' issues that emerged for blind and partially sighted people in Scotland.

Thurston, Thurston \& McLeod (2010) highlighted that where a person is on their sight loss journey may impact on the level of support that may be of most benefit to them. Using semi-structured interviews and the National Eye Institute Visual Functioning Questionnaire-25 with 18 people with sight loss, Thurston et al. identified a five stage transition process in adjusting to losing sight: moving from the first stage of shock, panic and disbelief on receiving a diagnosis of an eye condition which would lead to severe sight impairment to the fifth and final stage of accepting sight loss and reconceptualizing the self or the condition. The need for, and what is, effective psychological support may vary depending on the stage. For example, at stage one some form of immediate emotional support may prove helpful in dealing with the shock of diagnosis; at stage three counselling may help a person deal with the multiple losses they are experiencing.

To identify what provision of emotional support and counselling ought to look like, Royal National Institute of Blind People (RNIB) have constructed a three tier group 
framework (http://www.vision2020uk.org.uk/rnib-group-framework-for-emotionalsupport/ accessed 4/9/15)

- Tier 1 - eye clinic liaison officers, sight loss support workers, peer support programmes etc. Recognised pathways into tier 2 .

- Tier 2 - specialist counselling services, working with trained counsellors to help people with more serious psychological issues. Referral routes into tier 3.

- Tier 3 - acute mental health services, to help people with severe and enduring mental health issues compounded by sight loss

There is very little known about actual provision of emotional support and counselling for people affected by sight loss across the UK. This paper reports on a survey by the VISION 2020 UK Counselling and Emotional Support Services (CESS) Group, designed to gather information about what is provided, by whom and where.

\section{Methods}

Ethics

The procedures followed were in accordance with the British Association for Counselling and Psychotherapy's Ethical Guidelines for Researching Counselling and Psychotherapy (Bond, 2004).

Participants and procedure 
An online survey, designed by members of the VISION2020UK CESS group, aimed to capture information about current provision of emotional support and counselling for people affected by sight loss. Questions were designed to capture the geographical location of services across the UK, the availability of both emotional support and counselling, alongside information about service delivery and funding.

For the purposes of this survey emotional support was defined as 'The client is supported by a person in a helping role, who seeks to listen and to advise appropriately depending on the needs of the particular client' and counselling as 'Counselling and psychotherapy are umbrella terms that cover a range of talking therapies. They are delivered by trained practitioners who work with people over a short or long term to help them bring about effective change or enhance their wellbeing'. The survey was piloted with three services who gave feedback and minor amendments were made as a result.

The on line survey was publicised in two ways. First, a web-link to the survey was sent to services identified through the RNIB Sightline Directory (www.sightlinedirectory.org.uk), an on line searchable database of services for people with sight loss across the UK. The terms 'counselling' and 'emotional support' were used as search terms. After removing duplicates, an email invitation to complete the survey was sent to 149 services where an email address was provided. The request was for one response per service. Where one organisation provided services in several locations, the invitation was sent to a central contact for dissemination across the organisation. Second, a number of websites, newsletters, 
networks and E-bulletins were used to disseminate the web-link to the survey and invite participation, with publicity going out to most of these on two or more occasions. They included those within the sight loss sector, both 'in house' and cross organisation (for example the VISION2020 UK E-bulletin goes out to over 2500 recipients); and those targeting counsellors and therapists. The invite was also sent to the 249 people registered to receive updates from the VISION2020UK CESS Group.

The survey was open for six weeks during February and March 2014. As well as being able to complete online, in order to increase accessibility, the option to complete the survey by phone, was also offered, with an administrator completing the online tool on the respondents behalf. Two people took up this option.

There were 182 individual respondents.

Data were analysed descriptively using SPSS V21.

\section{Results}

\section{Profile of respondents}

Fifty per cent $(n=91)$ of respondents identified themselves as being from a voluntary sector organisation, typically a charitable organisation. A further $32 \%(n=58)$ were part of the National Health Service (NHS); with the remaining respondents consisting of a mix of private providers, social care and other types of settings. Of those identifying as being part of the NHS, 91.4\% $(n=53)$ were based within an eye clinic. 
Respondents were spread across the UK, with the highest representation in the South East $(14 \%, n=24)$ with all other regions of the UK represented by at least one service $(\operatorname{mean}=13, \min =1, \max =24)$.

Availability of emotional support and counselling

Table 1. The type of support provided

\begin{tabular}{|c|c|}
\hline Type of support provided & n (\%) \\
\hline Emotional support & $71(46.1 \%)$ \\
\hline Counselling & $7(4.6 \%)$ \\
\hline Counselling and emotional support & $61(39.6 \%)$ \\
\hline Neither but offer other support & $10(6.5 \%)$ \\
\hline Do not offer any emotional support or counselling & $5(3.3 \%)$ \\
\hline Total & $154(100 \%)$ \\
\hline
\end{tabular}

Emotional support was provided by $85.7 \%$ ( $n=132)$ of respondents, either alongside $(39.6 \%, n=61)$ or without $(46.1 \%, n=71)$ counselling. Counselling was provided by $44.2 \%(n=68)$ of respondents and was typically offered alongside emotional support. Counselling was offered without any other form of emotional support in $4.6 \%(n=7)$ of services (Table 1). 


\section{Emotional support}

Of those providing emotional support only, over $80 \%$ provided support in terms of 'signposting', 'information giving', 'advice giving' and 'someone to talk to' (Table 2). Just over a third of services providing emotional support only offered a befriending service.

Table 2. The type of emotional support and/or counselling provided

\begin{tabular}{|l|c|c|c|}
\hline & $\begin{array}{l}\text { Emotional support } \\
(\mathrm{n}=71)\end{array}$ & $\begin{array}{l}\text { Counselling and } \\
\text { emotional support } \\
(\mathrm{n}=61)\end{array}$ & $\begin{array}{l}\text { Counselling } \\
(\mathrm{n}=7)\end{array}$ \\
\hline Befriending & $26(36.6 \%)$ & $25(41 \%)$ & 0 \\
\hline Creative therapies & $5(7 \%)$ & $14(23 \%)$ & 0 \\
\hline Counselling/psychotherapy & $4(5.6 \%)$ & $49(80.3 \%)$ & $7(100 \%)$ \\
\hline Signposting & $61(85.9 \%)$ & $45(73.8 \%)$ & $4(57.1 \%)$ \\
\hline Information giving & $62(87.3 \%)$ & $41(67.2 \%)$ & $2(28.6 \%)$ \\
\hline Advice giving & $57(80.3 \%)$ & $35(57.4 \%)$ & 0 \\
\hline Someone to talk to & $61(85.9 \%)$ & $46(75.4 \%)$ & 0 \\
\hline Other & $811.3 \%)$ & $7(11.5 \%)$ & 0 \\
\hline
\end{tabular}

Note: percentages add up to more than $100 \%$ as respondents could select multiple options

Emotional support was typically provided by Eye Clinic Liaison Officers (ECLO) $(49.2 \%, n=58)$. An ECLO is usually based in a hospital eye clinic and works directly with people with sight loss, providing information, advice, emotional support and assistance in achieving an appropriate referral to community based services. 
However in $21.2 \%(n=25)$ of services this was provided by an 'unqualified colleague' (Table 3).

Table 3. Who provides emotional support.

\begin{tabular}{|c|c|c|c|}
\hline Provider & $\begin{array}{l}\text { Emotional support } \\
(\mathrm{n}=71)\end{array}$ & $\begin{array}{l}\text { Counselling and emotional } \\
\text { support }(n=61)\end{array}$ & Counselling $(n=7)$ \\
\hline $\begin{array}{l}\text { Social } \\
\text { workers }\end{array}$ & $3(4.2 \%)$ & 5 (8.2\%) & \\
\hline $\begin{array}{l}\text { Trained } \\
\text { volunteers }\end{array}$ & $8(11.3 \%)$ & $14(23 \%)$ & $1(14.3 \%)$ \\
\hline ECLO & $40(56.3 \%)$ & $18(29.5 \%)$ & \\
\hline $\begin{array}{l}\text { Professional } \\
\text { ly qualified } \\
\text { counsellor }\end{array}$ & $1(1.4 \%)$ & 31 (50.8\%) & $3(42.9 \%)$ \\
\hline $\begin{array}{l}\text { Peer } \\
\text { supporter }\end{array}$ & $7(9.9 \%)$ & $12(19.7 \%)$ & \\
\hline $\begin{array}{l}\text { Vision } \\
\text { rehabilitatio } \\
\text { n worker }\end{array}$ & $11(15.5 \%)$ & $13(21.3 \%)$ & \\
\hline $\begin{array}{l}\text { Unqualified } \\
\text { colleague }\end{array}$ & $11(15.5 \%)$ & $14(23 \%)$ & \\
\hline Other & $12(16.9 \%)$ & $5(8.2 \%)$ & $3(42.9 \%)$ \\
\hline
\end{tabular}

Despite the majority of emotional support provision being provided by ECLO's, only $56.5 \%(n=39)$ of respondents indicated that all of their ECLOs had completed the 
four day RNIB eye clinic support studies course, accredited by City University London (www.rnib.org.uk/eyeclinicstafftraining). 20.3\% $(n=14)$ indicated that none of their ECLO's had completed this course.

\section{Counselling}

Counselling or psychotherapy was typically delivered by a person centred $(45.8 \%$, $n=27)$ or integrative therapist $(44.1 \%, n=26)$, in $20.3 \%(n=12)$ services counselling was delivered by a cognitive behaviour therapist (CBT).

Fifty-three respondents provided information about whether the person delivering counselling interventions was a member of a professional body. The majority were members of a professional body $(74.1 \%, n=43)$, and were typically members of the British Association for Counselling and Psychotherapy (BACP) $(90.6 \%, n=48)$.

There was some degree of variability in terms of the minimum level of counselling qualification that therapists had obtained, with the majority $(22.6 \%, \mathrm{n}=12)$ having a further education (FE) diploma. However, a further $22.6 \%(n=12)$ of respondents did not know the minimum level of counselling qualification held by the counsellors working in their service and $5.7 \%(n=3)$ indicated the counselling/psychotherapy provided in their service was not delivered by a qualified practitioner. 
From 123 respondents, there was almost a 50:50 split in services indicating whether they provide continuing professional development to their practitioners.

\section{Access to emotional support and/or counselling services}

The majority of services $(57.5 \%, n=77)$ see between 1 and 10 clients per week, with $7.5 \%(n=10)$ of services seeing more than 50 clients per week.

Services were available to a wide range of clients, with the majority $(70.5 \%, n=91)$ being available to adults with a visual impairment. Services available to children were typically divided by age group, with $37.2 \%(n=48)$ services available for $0-11$ year olds and $45.7 \%(n=59)$ available to $11-18$ year olds (Table 4$)$.

Table 4. Who services are available to

\begin{tabular}{|l|r|r|}
\hline Who the service is available to & $\%$ & $\mathbf{n}$ \\
\hline Friends of someone with a visual impairment & 33.3 & 43 \\
\hline Children (0 - 11 years) with a visual impairment & 37.2 & 48 \\
\hline Children (11 - 18 years) with a visual impairment & 45.7 & 59 \\
\hline Adults with a visual impairment & 70.5 & 74 \\
\hline Older people with a visual impairment & 57.4 & 73 \\
\hline Family of someone with a visual impairment & 56.6 & 71 \\
\hline Those registered Sight Impaired (Partially sighted) & 55 & 71 \\
\hline Those registered Severely Sight Impaired (Blind) & 55 & 38 \\
\hline Anyone & & \\
\hline
\end{tabular}


Note: percentages add up to more than 100 as respondents could select multiple options

Services were provided in a range of different ways, with counselling typically being delivered face to face (Table 5).

Table 5. How services are delivered.

\begin{tabular}{|l|cc|}
\hline & \multicolumn{1}{|l|}{$\begin{array}{l}\text { Emotional } \\
\text { Support }\end{array}$} & Counselling \\
\hline \multirow{2}{*}{ Individual face-to-face } & $\begin{array}{l}74.2 \% \\
(n=98)\end{array}$ & \\
\hline & $22.7 \%$ & $14.7 \%(n=10)$ \\
Group & $(n=30)$ & $38.2 \%(n=26)$ \\
\hline & $65.2 \%$ & \\
\hline Telephone & $(n=86)$ & $5.9 \%(n=4)$ \\
\hline & $7.6 \%$ & \\
\hline
\end{tabular}

Note: percentages add up to more than $100 \%$ as respondents could select multiple options, percentages are calculated based on the total number of respondents indicating they offer either counselling or emotional support.

Waiting times to access counselling or emotional support varied considerably across services. Typically clients could expect to see a counsellor in $1-2$ weeks $(18.9 \%$, $\mathrm{n}=17)$, and could be provided emotional support in less than 1 week $(52.5 \% \mathrm{n}=53)$. However for one service there was a 6 month waiting list for counselling. 
Clients could be referred to services via a range of routes. For services providing counselling only $(n=7)$, the most common form of referral was self-referral $(71.4 \%$, $n=5)$. Services providing emotional support only $(n=71)$ were most likely to receive referrals via self-referral $(76.1 \%, n=54)$ or via an eye clinic $(78.9 \%, n=56)$, and services proving both counselling and emotional support similarly would receive the majority of their referrals via these routes, and also via vision rehabilitation officers $(64 \%, n=39)($ Table 6).

Table 6. Referral routes into services

\begin{tabular}{l|l|ll}
\hline & $\begin{array}{l}\text { Emotion } \\
\text { al }\end{array}$ & $\begin{array}{l}\text { Counselling } \\
\text { and Emotional }\end{array}$ & \\
& support & support & Counselling \\
\hline GP & $\begin{array}{l}40.9 \% \\
(n=29)\end{array}$ & $52.5 \%(n=32)$ & $28.6 \%(n=2)$ \\
\hline Self-referral & $\begin{array}{l}76.1 \% \\
(n=54)\end{array}$ & $70.5 \%(n=43)$ & $71.4 \%(n=5)$ \\
\hline Eye clinic & $\begin{array}{l}78.9 \% \\
(n=56)\end{array}$ & $63.9 \%(n=39)$ & $42.9 \%(n=3)$ \\
\hline $\begin{array}{l}\text { Vision } \\
\text { rehabilitation }\end{array}$ & $54.9 \%$ & & \\
officers & $(n=39)$ & $63.9 \%(n=39)$ & $28.6 \%(n=2)$ \\
\hline Local sight & & & \\
loss & $52.1 \%$ & & \\
organisations & $(n=37)$ & $47.5 \%(n=29)$ & $28.6 \%(n=2)$ \\
\hline
\end{tabular}




\begin{tabular}{|l|l|ll} 
Sensory & $52.1 \%$ & \\
support teams & $(n=37)$ & $59 \%(n=36)$ & 0 \\
\hline Other & $22.5 \%$ & \\
$(n=16)$ & $19.7 \%(n=12)$ & $14.3 \%(n=1)$ \\
\hline
\end{tabular}

Over $90 \%$ of services made onward referrals as appropriate to local/national counselling services, general medical practitioners (GPs), and within their own organisation. Respondents who made referrals to 'other' services included other charitable organisations, eye care teams and local hospital services.

\section{Presenting Issues for clients}

As presented in Figure 1, clients presented to services offering counselling only, emotional support only and both services for a wide range of issues. A high proportion of services not providing counselling, but only emotional support, were seeing clients who were presenting with issues such as depression (62\%) and anxiety (69\%) and a proportion of these services are also seeing clients who are presenting with issues related to self-harm (8.5\%). 
Figure 1. Presenting issues

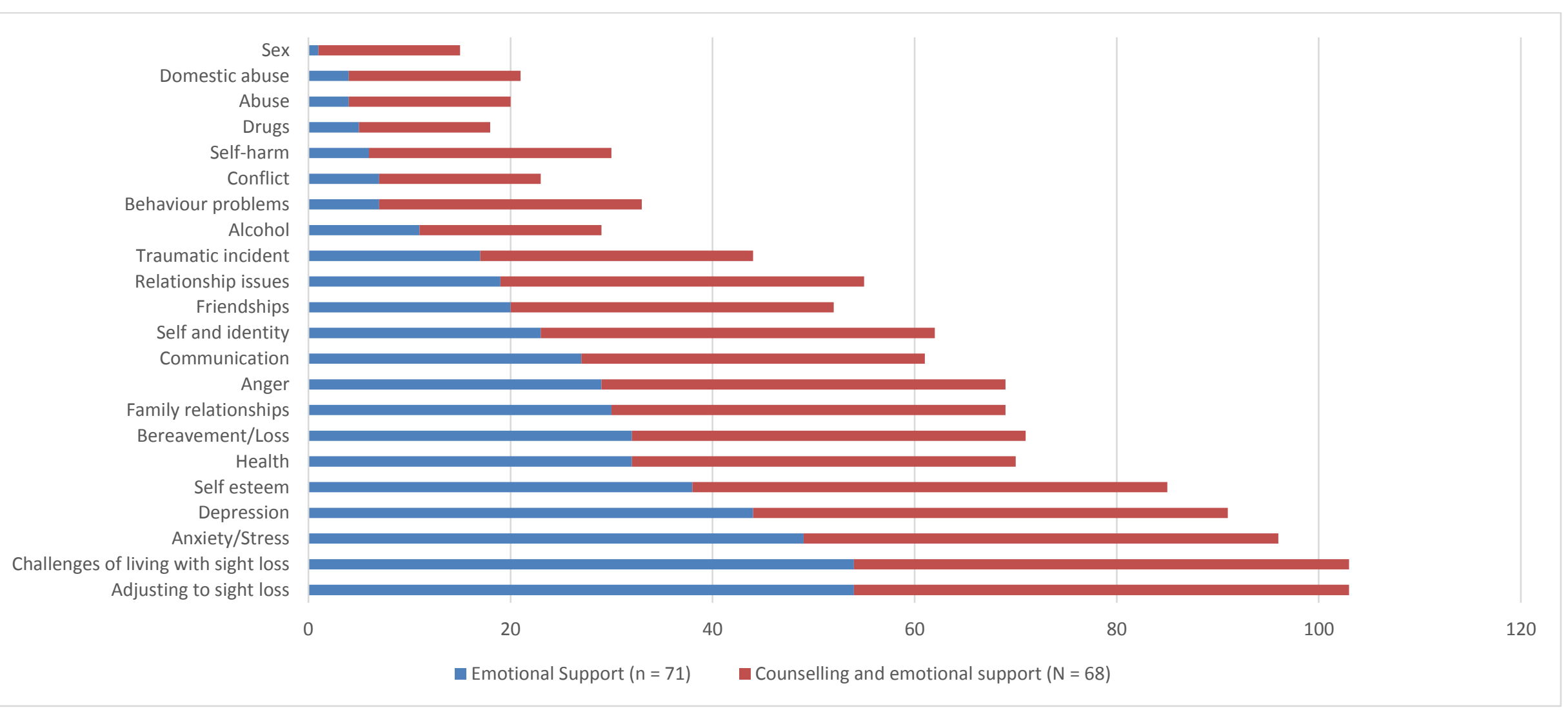


Outcome measures and service evaluation

Almost half of services responding to this question $(48.5 \%, n=63)$ indicated that they evaluate their service, with just over a quarter $(28.6 \%, n=18)$ collecting routine outcome data. Typically evaluations are used for service improvement $(77.8 \%, n=49)$ and reports for commissioners $(57.1 \%, n=36)$, but also to share best practice $(47.6 \%, n=30)$ and as a therapeutic tool $(25.4 \%, n=16)$.

Funding for services

Funding for services came from a wide range of sources, with the majority from charity core funding or the NHS. (Table 7)

Table 7. Funding for services

\begin{tabular}{|l|r|r|}
\hline & \% & n \\
\hline Charity core funding & 38.5 & 50 \\
\hline Charitable grants & 25.4 & 33 \\
\hline Local Authority & 30 & 39 \\
\hline NHS & 35.4 & 46 \\
\hline Other & 20 & 26 \\
\hline
\end{tabular}

Note: percentages add up to more than 100 as respondents could select multiple options 
$40.3 \%(n=52)$ of services responding to this question indicated they felt vulnerable or very vulnerable about funding for the future delivery of their service, with $25.6 \%$ $(n=33)$ feeling secure or very secure.

\section{Discussion}

The findings presented in this paper provide reassurance that there is some provision of emotional support and counselling for people affected by sight loss. In line with the RNIB Group Framework for Emotional Support, there appears to be some provision of tier 1 emotional support services, typically provided by Eye Clinic Liaison Officers (ECLO). However there is less provision of tier 2 specialist counselling services, with less than half of respondents offering this level of support. As this survey did not measure the need for such services it is not possible to assess whether current provision is sufficient to meet demand. The finding that waiting times were fairly short, at 1-2 weeks for both emotional support and counselling services, could be inferred to suggest that provision is meeting current demand. However, this survey also found the majority of referrals into emotional support and counselling services were self-referrals, suggesting eye clinics and GP's are not regularly referring people to such services throughout their sight loss pathway. We would advocate for the need for a national framework of emotional support and counselling, providing standardised support for all people affected by sight loss when needed. If this were available currently it is unclear if availability of emotional support and counselling services could meet an increase in demand for services. More research is needed to understand the throughput of clients to existing service provision. 
The 'Seeing it my way' consultation (UK Vision Strategy, 2011) found that people affected by sight loss wanted someone to talk to and for that support to be appropriate to their needs, which may differ along the sight loss pathway. This maps onto the 5 stage model of Thurston, Thurston and McLeod (2010). Emotional support and counselling needs to be available at the point of need, which may not be at the point of diagnosis for many people. Some clients may require and appreciate this type of support in the early stages of their diagnosis, for others the first priority may be learning to live physically with this change and the emotional impact of their diagnosis may not become apparent until much further down the line. For others support may be needed throughout their journey and the level of support required may change. There is a clear need for both emotional support and counselling to be available at the point of diagnosis but also as and when needed and therefore embedded into the sight loss care pathway. To ensure clients' needs are met there is a need for collaborative working amongst all professionals supporting people who are affected by sight loss, from GPs to ECLOs to Ophthalmologists. Every individual working to support the person affected by sight loss needs to understand the potential emotional impact that losing one's sight may have at any stage and to be able to signpost and refer to appropriate services as required. The current lack of any national framework for emotional support and counselling services in this context prevents services being required to meet a minimum standard, therefore there is the potential for services to provide support that may not be deemed appropriate if a national framework were in place. For example, in the present study although the vast majority of those providing counselling support were professionally qualified counsellors and members of a professional body, some respondents indicate someone who was not trained as a professional counsellor was providing this level 
of support. Furthermore, there is no requirement presently for counsellors/psychotherapists working with this client group to have undergone any specific training regarding sight loss. Research suggests it is very important to clients that the professionals they work with have an understanding of their sight loss (UK Vision Strategy, 2011; Thurston, McLeod \& Thurston, 2013). Similarly, despite there being available training for ECLO's providing emotional support, almost a quarter of respondents in the present study indicated their ECLO's had not completed this training. This is a concern and is something that a national framework may be able to address. Clients are presenting to services with a wide range of issues. Many of these may be expected, such as adjusting to their sight loss, and the challenges of losing their sight. However, many clients are presenting with issues such as depression, anxiety, self-harm, bereavement. These are issues that some services may not be equipped to deal with and are issues that ought best be supported by professionally qualified counsellors/psychotherapists. It is important that frontline staff are trained to recognise these issues in the person with sight loss and make appropriate referrals where required.

Funding is a concern for many services and is something that needs to be addressed.

\section{Limitations}

Although the reasonable sample size and the good cooperation from respondents is a significant strength of the paper, a potential limitation is that we cannot be clear what the response rate was from services across the UK, as there is no 
comprehensive list of counselling and support services. We do know that the response rate went beyond the 149 services listed on the RNIB Sightline Directory.

We are also aware that the survey has not captured information about the quality of services provided by respondents or the extent to which they meet the needs of the population of people who are VI.

\section{Future research}

Further research is required to better understand the quality and scope of the emotional support and counselling services currently available for blind and partially sighted people in the UK. This could be achieved by systematic evaluation of existing services. It is an assumption of this paper that services delivered by qualified practitioners would result in better client outcomes. Whilst this appears likely, it should be verified by further research in this area.

\section{Acknowledgements}

We acknowledge the support of Charlotte Knight (Thomas Pocklington Trust) in distributing and publicising the link to the survey and we wish to express our gratitude to the members of the VISION2020UK Counselling and Emotional Support Service group for their valuable guidance throughout.

\section{Declaration of Conflicting Interests}

The Authors declare that there is no conflict of interest.

\section{Funding}


This research received no specific grant from any funding agency in the public, commercial, or not-for-profit sectors.

\section{References}

Access Economics Pty Ltd. (2009) Future Sight Loss UK 1: The economic impact of partial sight and blindness in the UK adult population. London: RNIB.

Bond (2004) Ethical guidelines for researching counselling and psychotherapy. Lutterworth: British Association for Counselling and Psychotherapy

Brody, B.L., Gamst, A.C., Williams, R.A., Smith, A.R., Lau, P.W., Brown, S.I. (2001) Depression, visual acuity, comorbidity, and disability associated with age-related macular degeneration. Ophthalmology, 108 (10) 1893-1900.

Cairns, C., Herriotts, P., Douglas, G., Corcoran, C. \& Pavey, S. (2009) Network 1000 Scotland: a report on the opinions and circumstances of blind and partially sighted people in Scotland. British Journal of Visual Impairment 27 (3) 239-51.

Evans, J.R., Fletcher, A.E., \& Wormald, R.P.L. (2007) Depression and anxiety in visually impaired older people. Ophthalmology 114 (2) 283-288.

Gosney, M.A., Victor, C.R. \& Nyman SR (2010) Emotional Support to People with Sight Loss. Occasional Paper 26. Thomas Pocklington Trust. 
McManus, S. \& Lord, C. (2012) Circumstances for people with sight loss: secondary analysis of Understanding Society and the Life Opportunities Survey. NatCen report for RNIB.

Osborn DPJ, Fletcher AE, Smeeth L, Stirling S, Bulpitt CJ, Breeze E, Ng ESW, Nunes M, Jones D, Tulloch A. (2003) Factors associated with depression in a representative sample of 14217 people aged 75 and over in the United Kingdom: results from the MRC trial of assessment and management of older people in the community. International Journal of Geriatric Psychiatry 18 (7) 623-630.

RNIB Group Framework for Emotional Support. Available from:

\section{http://www.vision2020uk.org.uk/rnib-group-framework-for-emotional-support/} [accessed $4^{\text {th }}$ Sept 2015].

Thurston, M., Thurston, A. \& McLeod, J. (2010) The socio-emotional effects of the transition from sight to blindness. The British Journal of Visual Impairment. 28 (2), 90-112.

Thurston, M., McLeod J. \& Thurston, A. (2013). Counselling for sight loss: Using systematic case study research to build a client informed practice model. British Journal of Visual Impairment. 31(2), 102-122.

UK Vision Strategy (2011) Seeing it my way. UK Vision Strategy. 
Waern M., Rubenowitz E, Runeson B, Skoog I, Wilhelmson K, Allebeck P. (2002) Burden of illness and suicide in elderly people: case-control study. British Medical Journal 324(7350):1355-1357. 